\title{
INTEGRATED ZETA - FLYBACK CONVERTER TO SUPPLY HID LAMPS
}

\author{
Tiago B. Marchesan ${ }^{1}$, Marco Dalla Costa ${ }^{2}$, J. Marcos Alonso ${ }^{2}$ and Ricardo N. Prado ${ }^{1}$ \\ 1. Electronic Ballast Research Group - GEDRE,PPGEE, Universidade Federal de Santa Maria, RS, Brazil. \\ 2. Universidad de Oviedo, DIEECS, Tecnología Electrónica, Campus de Viesques,Gijón, Spain. \\ rnprado@ieee.org
}

\begin{abstract}
This paper proposes a Metal Halide (MH) lamp electronic ballast based on the integration of Zeta and Flyback converters working in discontinuous conduction mode, in order to provide the ballast power factor correction and to stabilize the lamp current, respectively. The proposed integration besides to reduce the number of ballast components, presents no additional current stress in the shared switch. The lamp is supplied with a low frequency square waveform $(400 \mathrm{~Hz})$ to avoid the acoustic resonance phenomenon. The proposed topology has been implemented for an input voltage of $110 \mathrm{~V}, 50 \mathrm{~Hz}$, in order to supply a $35 \mathrm{~W}$ MH lamp.
\end{abstract}

Keywords - Acoustic resonance, electronic ballast, HID lamps, integrated circuits.

\section{INTRODUCTION}

Metal Halide (MH) lamps have proven to be suitable for indoor applications due to their characteristics of high color rendering index (CRI) and high luminous efficacy (around $100 \mathrm{~lm} / \mathrm{W})$. Besides, in order to achieve good efficiency, no light flicker, audible noise absence, and compact size, these lamps must be supplied by electronic ballasts. However, the operation of these lamps under high frequency current waveforms is susceptible to the occurrence of the acoustic resonance (AR) phenomenon. When the frequency imposed to the lamp is increased and an eigenfrequency is approached, pressure waves become propagational and disturb the discharge path [1]. So, supplying these lamps with a highfrequency (20 to $100 \mathrm{kHz}$ ) sinusoidal waveform, as it is done usually with low pressure discharge lamps, such as fluorescent lamps is a difficult task.

Many alternatives have been proposed to avoid the AR, e.g.: avoiding the frequencies where the AR appears by means at low-frequency square-waveform (LFSW) ballasts [2] or extra-high-frequency ballasts [3]; lamp operation in a free-resonance window [4]; high-frequency square-waveform supply [5]; lamp operation with suitable frequency modulated waves, where the threshold value to excite the AR is not achieved [6]; and lamp operation with sinusoidal waveform superposed with third harmonic [7].

The use of a low frequency square waveform (LFSW) to supply the lamp is an option adopted by many researchers in order to deliver constant power to the lamp and avoid the AR occurrence. Conventionally, in this way, a three stages electronic ballast is needed, where: 1) Power factor correction stage (PFC); 2) Lamp power control stage (LPC); and 3) Inverter stage. So, as can be seen, this solution leads to a complex circuit that requires a high number of components, what increases the power losses and the ballast final cost. One of the ideas proposed in the literature to solve the problem is the integration of power stages in order to reduce the number of components of the electronic ballast, thus becoming more attractive to the industry [8-11].

In this way, a single-stage electronic ballast is presented, which consists of integrating a Zeta converter to provide the PFC and a Flyback converter to control the lamp power, without additional current stress in the main switch. The Flyback inductor includes two secondary windings that work complementary to supply the lamp with a LFSW current.

\section{PROPOSED INTEGRATION}

When two converters are integrated some disadvantages have to be faced. For example, in the integrated topologies proposed in [8], the current handled by the shared switch is the addition of the current of each integrated stage. On the other hand, even though the integration proposed in [9] avoids this effect, the design of this topology for low-voltage mains $(90-110 \mathrm{~V})$ is very difficult due to the high dependence of the power factor (PF) on the difference between the main voltage and bus voltage.

The solution proposed in this work is the integration of a Zeta and a Flyback converter working in a discontinuous conduction mode (DCM). The shared switch handles only one of the converter currents instead of their addition. Moreover, the input characteristics of the Zeta converter allow it to be used to all range of input voltages (90V 220V).

The proposed topology is shown in Figure 1, which excludes the rectifier stage that is formed by $D_{1}-D_{4}$ diodes arranged in a single-phase bridge.

The Zeta converter is implemented in the PFC stage, and the Flyback converter is used to guarantee the lamp desired operation.

The use of the Flyback converter in the LPC stage allows the employment of a Half-Bridge inverter to provide the alternating lamp current (square waveform).

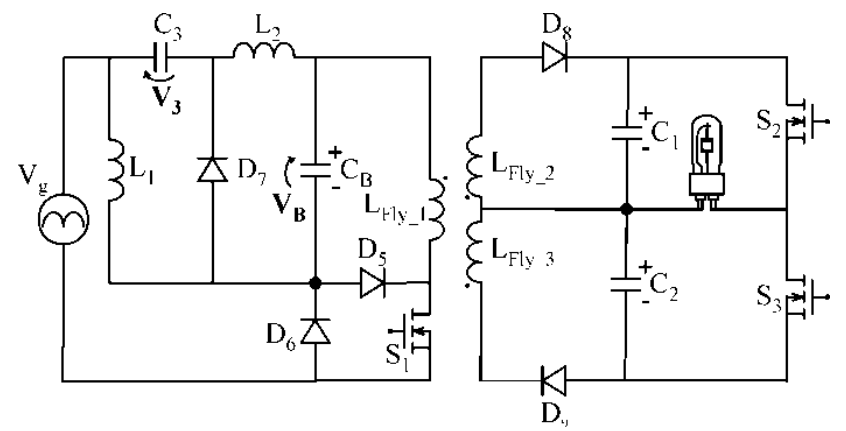

Fig. 1. Proposed electronic ballast topology.

Manuscript received on 07/03/2008. Revised on 14/07/2008. Accepted by recommendation of the Editor Fernando L. M. Antunes. 
To understand how the current is distributed among the main switch $\left(\mathrm{S}_{1}\right)$ and diodes $\mathrm{D}_{5}$ and $\mathrm{D}_{6}$, the equivalent circuit shown in Figure 2 can be depicted.

In this circuit, it can be seen that switch $\mathrm{S}_{1}$ will handle only the highest current between the two integrated converters $\left(i_{\text {Fly }}\right.$ or $\mathrm{i}_{\mathrm{L} 1}+\mathrm{i}_{\mathrm{L} 2}$ ). The diode in parallel with the highest current will be open, whereas the diode in parallel with the lowest current will be close. Since the operation is in DCM, the two Zeta and Flyback currents are ramp waveforms starting at the same instant. During one line half period the switch can handle either the Flyback or the Zeta current, because in a specific operation point the Flyback current ramp is nearly constant and will be affected only by the dc bus voltage ripple, and the Zeta current ramp will depend on the instantaneous line voltage value. Therefore, the conclusion is that the current through switch $\mathrm{S}_{1}$ will be either $\mathrm{i}_{\mathrm{Fly}}$ or $\mathrm{i}_{\mathrm{L} 1}+\mathrm{i}_{\mathrm{L} 2}$, whichever is higher, but not the addition of the two currents.

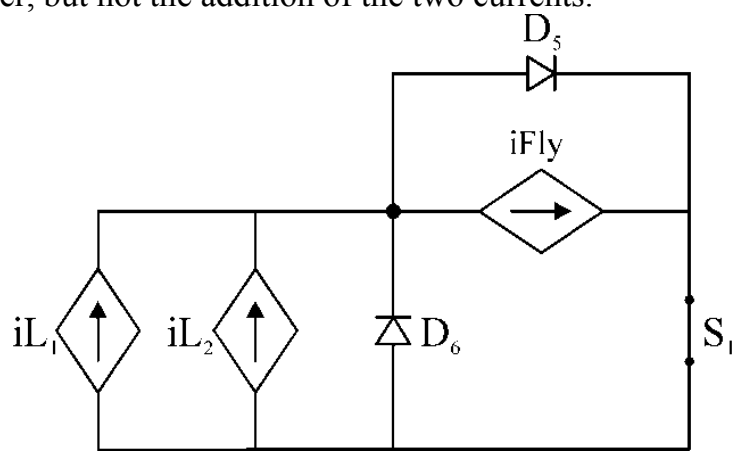

Fig. 2. Equivalent circuit during conduction of $\mathrm{S}_{1}$.

\section{OPERATION MODES}

The operation modes of the proposed integration are analyzed through the theoretical waveforms in Figure 3 and illustrated in Figure 4. Both converters operate in a DCM and the load of the integrated stages is considered to be the inverter + lamp.

\section{A. Mode I or II}

These modes begin when the main switch $S_{1}$ in turned on. The voltage $V_{3}$ is equal to $V_{B}$. So, the input voltage is applied to the both inductors of Zeta converter $\left(\mathrm{L}_{1}\right.$ and $\left.\mathrm{L}_{2}\right)$.

Currents $i_{L 1}$ and $i_{L 2}$ increase linearly. At the same time, voltage $\mathrm{V}_{\mathrm{B}}$ is applied to $\mathrm{L}_{\mathrm{Fly}_{-} 1}$ charging the Flyback coupled inductors. When $\left(\mathrm{i}_{\mathrm{L} 1}+\mathrm{i}_{\mathrm{L} 2}\right)>\mathrm{i}_{\text {Fly }}$ the mode I shown in Figure4 takes place. On the other hand, when $\left(\mathrm{i}_{\mathrm{L} 1}+\mathrm{i}_{\mathrm{L} 2}\right)<\mathrm{i}_{\mathrm{Fly}}$ the converter operation is in mode II.

These cases can be better analyzed through the theoretical waveforms shown in Figure 3. In the case that $\left(i_{L 1}+i_{L 2}\right)>i_{F l y}$ the shared switch $\left(\mathrm{S}_{1}\right)$ handle $\left(\mathrm{i}_{\mathrm{L} 1}+\mathrm{i}_{\mathrm{L} 2}\right)$ current. It occurs when the input voltage is near to its highest value. On the other hand, when $\left(\mathrm{i}_{\mathrm{L} 1}+\mathrm{i}_{\mathrm{L} 2}\right)<\mathrm{i}_{\text {Fly }}$ the current handled by the shared switch is $i_{\text {Fly }}$. So, depending on the operation point along to the variation of the input voltage mode I or II can takes place.

The lamp during these modes is supplied by the energy stored in capacitor $\mathrm{C}_{1-2}$.

\section{B. Mode III}

In this mode switch $\mathrm{S}_{1}$ is turned off. The currents through inductors $\mathrm{L}_{1}$ and $\mathrm{L}_{2}$ decrease linearly through diode $\mathrm{D}_{7}$, as can be seen in the theoretical waveforms in Figure 3. The value of inductance $\mathrm{L}_{1}$ is projected to be lower than $\mathrm{L}_{2}$. So, as they are submitted to the same discharge voltage $\left(\mathrm{V}_{\mathrm{B}}=\mathrm{V}_{3}\right)$, the current through inductor $\mathrm{L}_{1}$ reaches zero faster than that through $\mathrm{L}_{2}$, and then it becomes negative until $\mathrm{i}_{\mathrm{L} 2}=-\mathrm{i}_{\mathrm{L} 1}$. At this instant $\mathrm{D}_{7}$ stops conducting and mode IV begins.

In the LPC stage, the energy stored in the coupled inductors of Flyback converter is now discharged to capacitor $\mathrm{C}_{1-2}$ and inverter + lamp.

\section{Mode IV}

This is a freewheeling mode. When $\mathrm{i}_{\mathrm{L} 2}=-\mathrm{i}_{\mathrm{L} 1}$ diode $\mathrm{D}_{7}$ is out of conduction and as $V_{3}=V_{B}$ the current in both inductors remains constant. During this stage the load is supplied by the energy stored in $\mathrm{C}_{1-2}$.

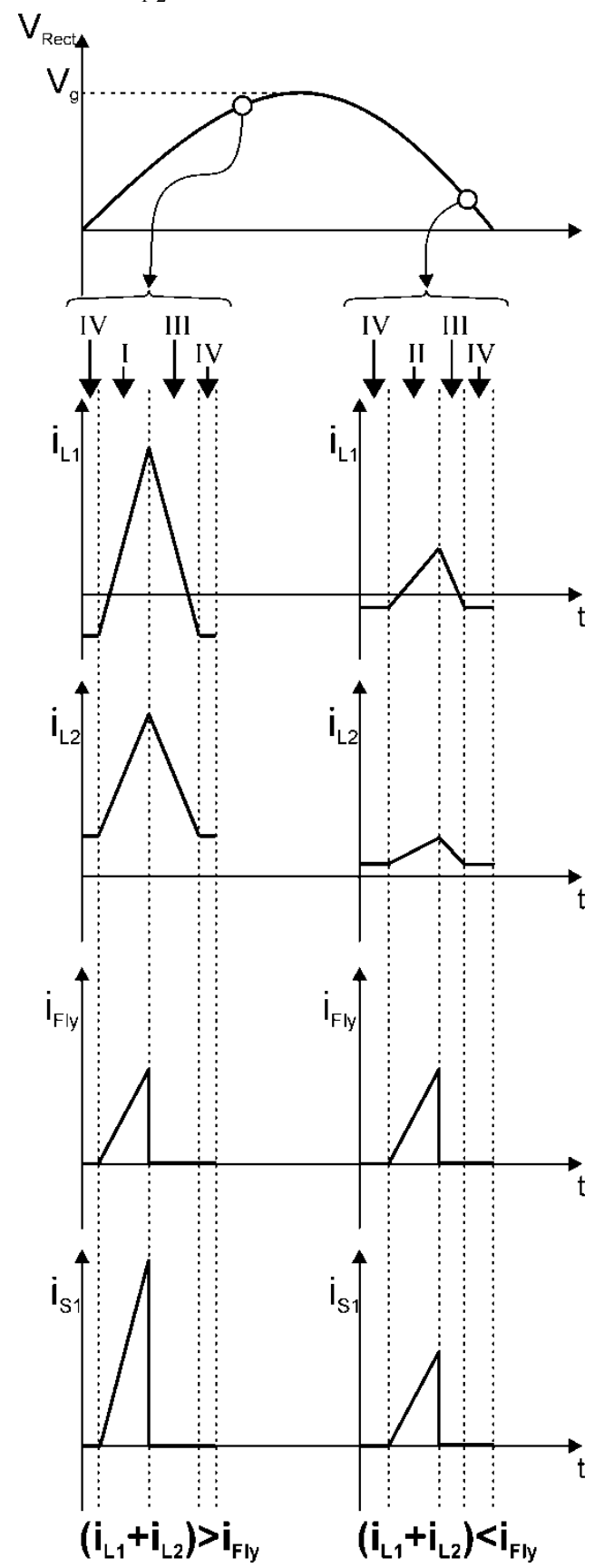

Fig. 3. Theoretical waveforms for both cases: $\left(i_{L 1}+i_{L 2}\right)>i_{\text {Fly }}$ and $\left(\mathrm{i}_{\mathrm{L} 1}+\mathrm{i}_{\mathrm{L} 2}\right)<\mathrm{i}_{\mathrm{Fly}}$. 


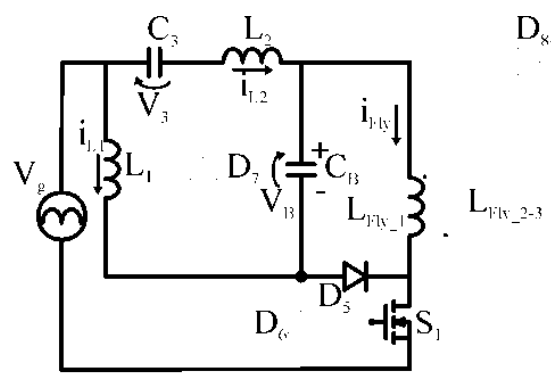

MODE I

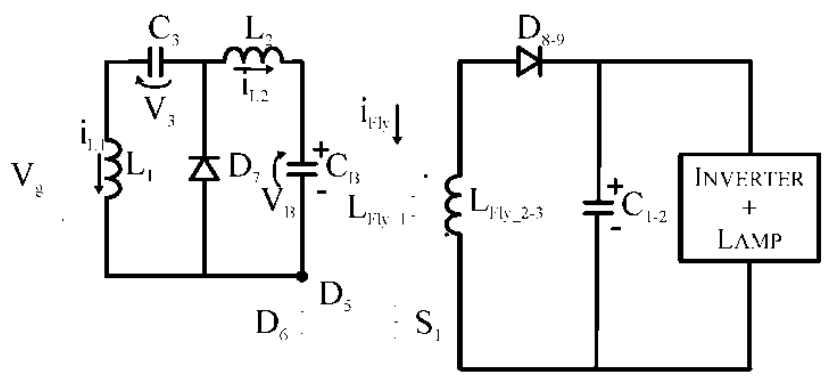

MODE III

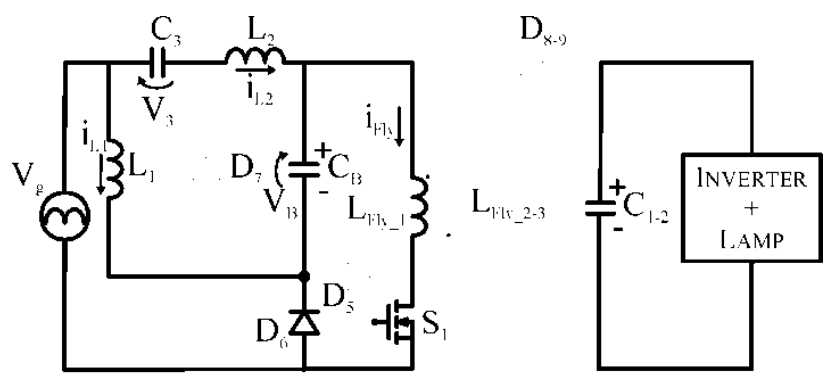

MODE II

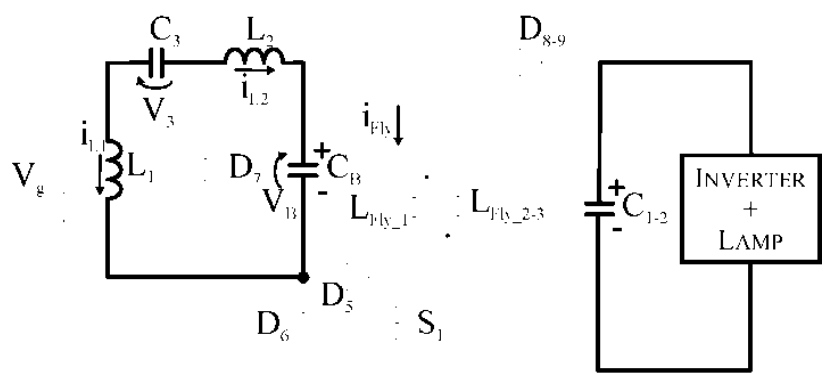

MODE IV

Fig. 4. Electronic ballast operation modes.

\section{DESIGN OF THE PROPOSED INTEGRATED CONVERTER}

Figure 5 illustrates the low frequency equivalent circuit of the proposed converter for an idealized situation (efficiency equal to $100 \%$ ). This circuit is used to analyze the characteristic of the bulk capacitor voltage $\left(V_{B}\right)$, which is the common voltage of PFC and LPC stages. In this way, as both converters operate in DCM, they can be represented by their equivalent input resistances $\mathrm{R}_{\mathrm{Fly}}$ and $\mathrm{R}_{\mathrm{Zeta}}$, which can be expressed, according [9], as follows:

$$
\begin{gathered}
R_{\text {Fly }}=\frac{2 \cdot L_{\text {Fly_1 }}}{D^{2} \cdot T_{s}} \\
R_{\text {Zeta }}=\frac{2 \cdot L_{e}}{D^{2} \cdot T_{s}}
\end{gathered}
$$

where $\mathrm{D}$ is the duty cycle, $\mathrm{T}_{\mathrm{s}}$ is the switching period, $\mathrm{L}_{\mathrm{Fly} 1} 1$ is the primary Flyback inductance and $\mathrm{L}_{\mathrm{e}}$ is the Zeta equivalent inductance $\left(\mathrm{L}_{1} / / \mathrm{L}_{2}\right)$.

The output current of the Zeta converter $i_{B}(t)$ can be calculated by equaling input and output powers. The following expression is obtained:

$$
i_{B}(t)=\frac{1}{2} \cdot \frac{V_{g}^{2} \cdot D^{2} \cdot T_{s}}{V_{B} \cdot L_{e}} \cdot(\sin \omega \cdot t)^{2}
$$

where $\mathrm{V}_{\mathrm{g}}$ is the input voltage peak value.

The dc component of this current, $\mathrm{I}_{\mathrm{B}}$, can be obtained by integration, as follows:

$$
I_{B}=\frac{1}{\pi} \cdot \int_{0}^{\pi} i_{B}(t) \cdot d t=\frac{1}{4} \cdot \frac{V_{g}^{2} \cdot D^{2} \cdot T_{s}}{V_{B} \cdot L_{e}} .
$$

Finally, the bulk capacitor voltage can be derived. Assuming negligible voltage ripple, it can be approximated by its dc component, as shown in the following equation:

$$
V_{B}=I_{B} \cdot R_{F l y}=\frac{1}{2} \cdot \frac{V_{g}^{2} \cdot L_{F l y \_} 1}{V_{B} \cdot L_{e}}
$$

The following parameters are defined for simplification:

$$
m=\frac{V_{g}}{V_{B}}
$$

and

$$
\alpha=\frac{L_{e}}{L_{\text {Fly_1 }}}
$$

Using (6) and (7) in (5), the following expression is obtained:

$$
\alpha=\frac{1}{2} \cdot m^{2}
$$

Therefore, as shown by (8), the operation of the integrated stages in DCM makes the dc bus voltage $\left(\mathrm{V}_{\mathrm{B}}\right)$ independent on load, duty ratio and switching frequency; it only depends on the ac input voltage and the ratio between the Zeta and Flyback inductances $(\alpha)$.

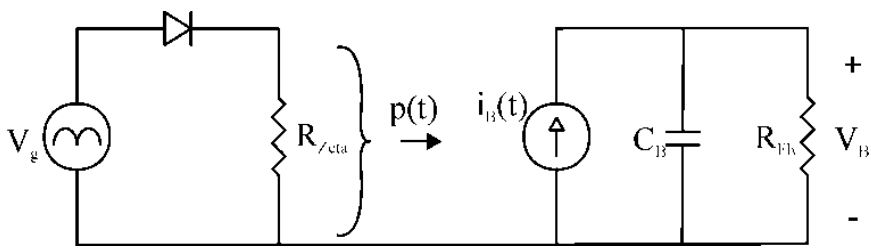

Fig. 5. Low frequency equivalent circuit of the proposed ballast. 
Equation (8) has been plotted in Figure 6, which is the main characteristic to carry out the design of the proposed converter.

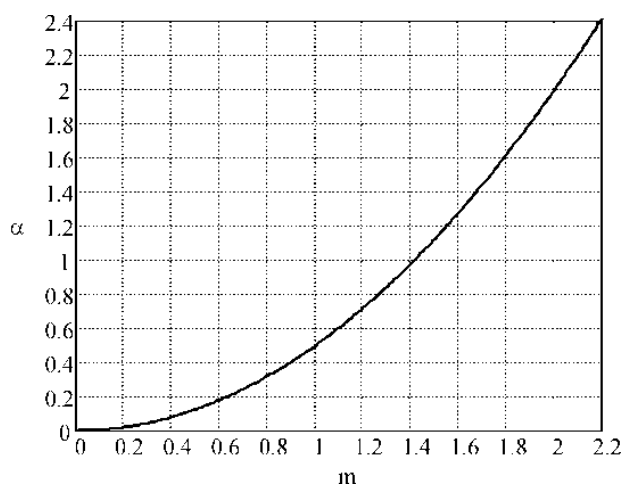

Fig. 6. Voltage ratio $\mathrm{m}$ as a function of the inductance ratio $\alpha$.

The Flyback inductances need to be designed to guarantee the operation of the converter in a DCM, and are calculated according to the procedure presented in [9]. After that, Zeta equivalent inductance $\mathrm{L}_{\mathrm{e}}$ can be calculated from (7).

Now, to calculate the value of $L_{1}$ and $L_{2}$ inductances of Zeta converter a maximum peak to peak current ripple $\left(\Delta \mathrm{i}_{\mathrm{B}}\right)$ in $\mathrm{L}_{2}$ must be chosen. It is defined by the following equation:

$$
\Delta i_{B}=\frac{V_{g} D T_{s}}{L_{2}}
$$

Representing equation (3) as:

$$
i_{B}(t)=I_{B_{-} P}(\sin \omega t)^{2}
$$

where $I_{B_{-} P}$ is the $i_{B}(t)$ current peak value. The current ripple factor $(\delta)$ is defined as follows:

$$
\delta=\frac{\Delta i_{B}}{I_{B_{-} P}} .
$$

Therefore, using, (3), (9), (10) and (11), the $\mathrm{L}_{2}$ value can be calculated:

$$
L_{2}=\frac{2 L_{e}}{\delta m D}
$$

And, consequently, as $\mathrm{L}_{\mathrm{e}}=\mathrm{L}_{1} / / \mathrm{L}_{2}$,

$$
L_{1}=\frac{2 L_{e}}{2-\delta m D}
$$

Another important issue that must be analyzed before a complete design can be performed is the voltage ripple across the bulk capacitor $\left(\Delta V_{B}\right)$, which must be limited to an appropriate value. The peak-to-peak voltage ripple across the bulk capacitor can be calculated as follows:

$$
\Delta V_{B}=\frac{\Delta Q}{C_{B}}=\frac{1}{2 \omega C_{B}} \int_{0}^{\pi}\left|i_{B}(t)-I_{B}\right| d t
$$

The bus voltage ripple factor (r) is defined below:

$$
r=\frac{\Delta V_{B}}{V_{B}}
$$

Then, according to a desired bus voltage ripple, the capacitor $\mathrm{C}_{\mathrm{B}}$ value can be calculated:

$$
C_{B}=\frac{m^{2} D^{2} T_{s}}{8 \pi L_{e} f r},
$$

where $f$ is the line frequency.

\section{DESIGN EXAMPLE AND EXPERIMENTAL RESULTS}

Considering the previously described analysis and equations, an electronic ballast is projected and implemented for an input voltage of $110 \mathrm{~V}, 50 \mathrm{~Hz}$, in order to supply a $35 \mathrm{~W}$ MH lamp. The electronic ballast was designed to have a voltage ratio of $\mathrm{m}=1.55$, resulting in the relation between the inductances $\alpha=1.2$, as can be obtained from the graphic in Figure 6.

The Flyback inductances, designed according to [9], to guarantee the operation in a DCM are: $\mathrm{L}_{\mathrm{Fly}_{-}}=223 \mu \mathrm{H}$ and $\mathrm{L}_{\mathrm{Fly}_{2} 2}=\mathrm{L}_{\mathrm{Fly} 3} 3=512 \mu \mathrm{H}$.

Considering (12) and (13) the Zeta inductances $\mathrm{L}_{1}$ and $\mathrm{L}_{2}$ are calculated to be $362 \mu \mathrm{H}$ and $1 \mathrm{mH}$, respectively. The converters switching frequency is $80 \mathrm{kHz}$ and the duty cycle for the steady state operation is around $37 \%$.

The projected values and employed components are presented in table I.

TABLE I

Commercial Components

\begin{tabular}{cc}
\hline $\mathrm{D}_{5}, \mathrm{D}_{6}, \mathrm{D}_{7}, \mathrm{D}_{8}$ and $\mathrm{D}_{9}$ & UF4007 \\
\hline $\mathrm{C}_{\mathrm{B}}$ & $\begin{array}{c}\text { Electrolytic capacitor } \\
250 \mu \mathrm{F} / 250 \mathrm{~V}\end{array}$ \\
\hline $\mathrm{S}_{1}$ & IRFPE50 \\
\hline $\mathrm{S}_{2}$ and $\mathrm{S}_{3}$ & IRF840 \\
\hline $\mathrm{C}_{1}=\mathrm{C}_{2}$ & Polypropylene capacitor \\
& $220 \mathrm{nF} / 630 \mathrm{~V}$ \\
\hline $\mathrm{C}_{3}$ & Polypropylene capacitor \\
& $100 \mathrm{nF} / 630 \mathrm{~V}$ \\
\hline
\end{tabular}

Some experimental results are illustrated in Figures. 7, 8, 9, 10, 11 and 12. Figure 7 shows the input line voltage and current, where an input power factor of 0.998 is obtained. Figure 8 shows the lamp voltage and current $(400 \mathrm{~Hz})$. As previously described the lamp is operated with a LFSW to avoid the acoustic resonance phenomenon.

Figure 9 presents the current handled by the shared switch. As can be seen this current is not the addition of the two stages current but the highest current of each stage. The shared switch peak voltage and current is shown in detail in Figure 10.

Figure 11 presents the inductors current of Zeta converter. The maximum output current ripple $\left(\Delta \mathrm{i}_{\mathrm{B}}\right)$ in $\mathrm{L}_{2}$ is calculated to be $800 \mathrm{~mA}$. As can be seen, the $\mathrm{L}_{1}$ inductor value is able to guarantee the DCM of the converter.

The bus capacitor voltage is shown in Figure 12. It is calculated to a voltage ripple (r) of approximately $5 \%$. Its value is $220 \mu \mathrm{F}$. 


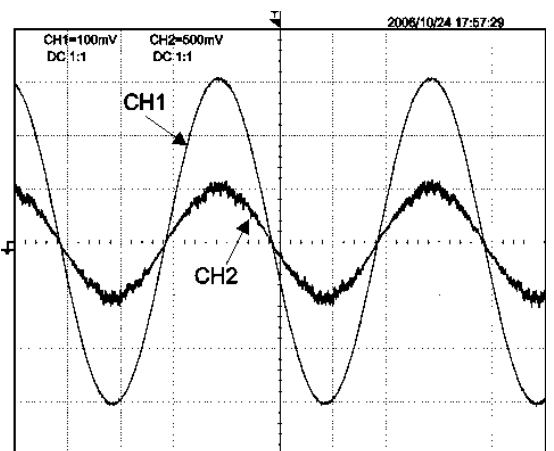

Fig. 7. Input voltage (CH1-50V/div) and current (CH2-500mA/div), $5 \mathrm{~ms} / \mathrm{div}$.

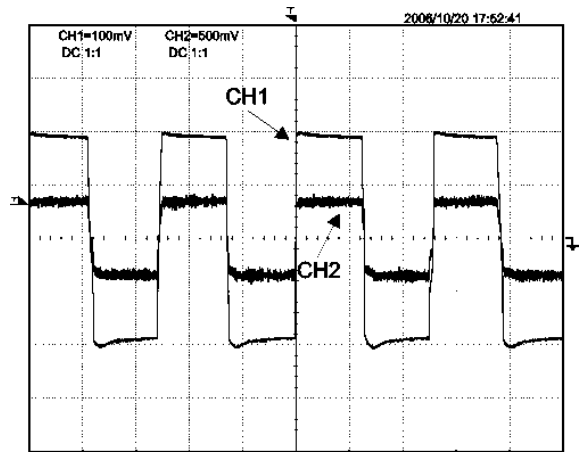

Fig. 8. Lamp voltage (CH1-50V/div) and current (CH2$500 \mathrm{~mA} / \mathrm{div}), 1 \mathrm{~ms} / \mathrm{div}$.

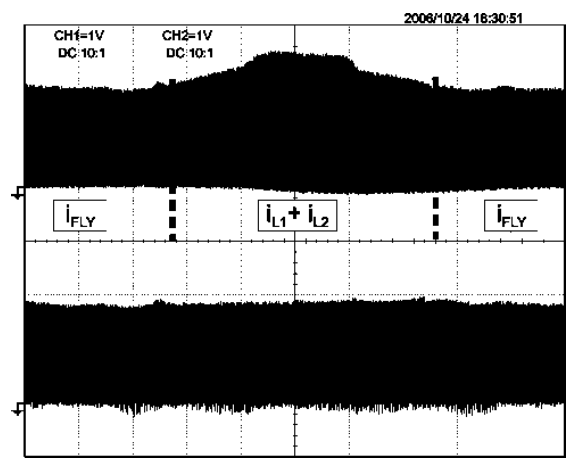

Fig. 9. Shared switch current (top trace $-1 \mathrm{~A} / \mathrm{div}$ ) and primary Flyback current (bottom trace $-1 \mathrm{~A} / \mathrm{div}$ ), $1 \mathrm{~ms} /$ div .

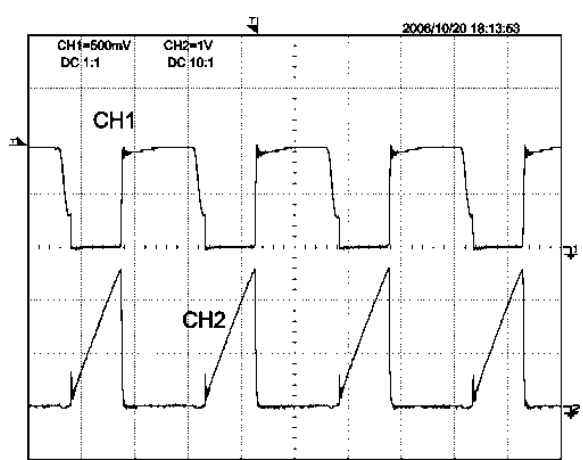

Fig. 10. Shared switch voltage (CH1-250V/div) and current (CH2$1 \mathrm{~A} / \mathrm{div}), 5 \mu \mathrm{s} / \mathrm{div}$.

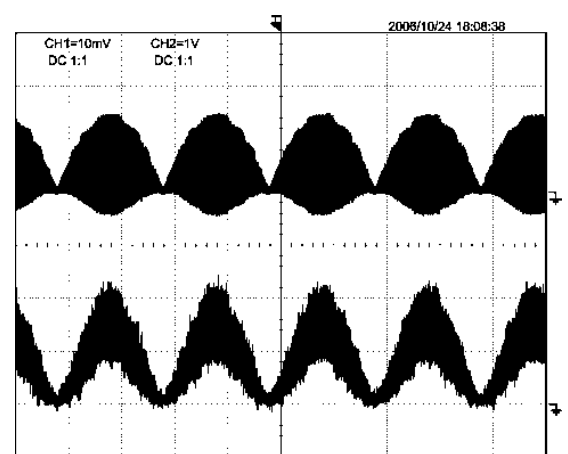

Fig. 11. Zeta converter inductors current: $\mathrm{L}_{1}$ (top trace - 1A/div) and $\mathrm{L}_{2}$ (bottom trace $-500 \mathrm{~mA} / \mathrm{div}$ ), $5 \mathrm{~ms} / \mathrm{div}$.

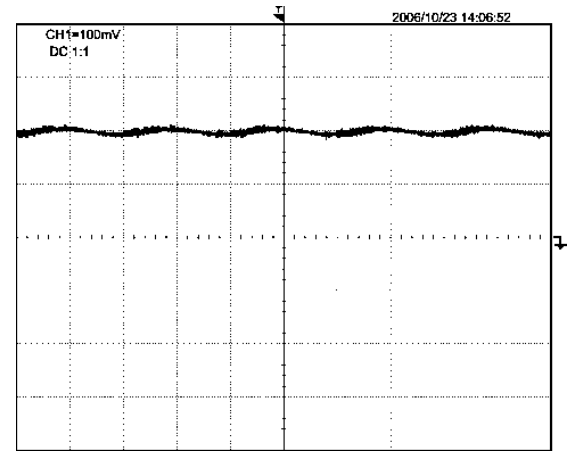

Fig. 12. Bus capacitor voltage (50V/div), $5 \mathrm{~ms} / \mathrm{div}$.

\section{CONCLUSION}

The integration of power stages to supply MH lamps is pointed as a solution to reduce the ballast final cost and to increase its efficiency. Considering the integration of the PFC and LPC stages, an electronic ballast based on the Zeta converter is proposed where the shared switch does not handle the addition of the both stages currents, thus reducing losses and increasing the ballast efficiency. The experimental results validate the proposed configuration, and demonstrate that the proposed electronic ballast is able to provide the desired lamp operation waveforms, while the input current harmonics are in agreement with IEC-61000-3-2 standard. The efficiency of the proposed electronic ballast is around $83 \%$ in steady state operation.

Experimental results for this configuration are obtained in [12] for a mains of $220 \mathrm{Vrms} / 60 \mathrm{~Hz}$ to supply an OSRAM Vialox 70W HPS lamp. The efficiency obtained in that case is $86 \%$ employing a COOLMOS SPW17N80C2 in the shared switch. The results show that increasing the input voltage and the output power the efficiency increase. However, the high number of magnetic components of zeta converter penalty the electronic ballast efficiency.

\section{ACKNOWLEDGMENT}

This work was supported by CAPES, Brazil under the scholarship process number BEX 12-100/68 and Spanish Government under research grant number DPI-2003-00308. 


\section{REFERENCES}

[1] J. J. de Groot and J. A. J. M. van Vliet, THE HIGHPRESSURE SODIUM LAMP. Philips technical library. MacMillan Education, 1986.

[2] M. Shen, Z. Qian, and F. Z. Peng, "Design of a TwoStage Low-Frequency Square-Wave Electronic Ballast for HID Lamps," IEEE Trans. on Industry Applications, vol. 39, no. 2, March/April 2003.

[3] H. Ohguchi, T. Shimizu, H. Takagi, M. H. Ohsato, Q. Mao, and G. Kimura, "Megahertz Operation of Voltage-Fed Inverter for HID Lamps Using Distributed Constant Line," IEEE Trans. on Industry Applications, vol. 34, no. 4, July/August 1998, pp. 747751.

[4] Y. Koshimura, N. Aoike, H. Kobayashi and O. Nomura, "Several Ways for Stabilizing HID Lamps Operation on High Frequency Power." Journal of Illum. Eng. Inst. of Japan, vol. 67, no. 2, 1983, pp. 55-61.

[5] M. Ponce, A. Lopez, J. Correa, J. Arau and J. M. Alonso, "Electronic Ballast for HID Lamps with High Frequency Square Waveform to Avoid Acoustic Resonance." IEEE Applied Power Electronics Conference and Exposition (APEC'01) proceedings, vol. 2, 4-8 March, 2001, pp. 658-663.

[6] L. Laskai, P. N. Enjeti and I. J. Pitel, "White-Noise Modulation of High-Frequency High-Intensity Discharge Lamp Ballasts," IEEE Trans. on Industry Applications, vol. 34, no 3, May/June 1998.

[7] J. M. Alonso, J. Ribas, M. Rico-Secades, J. G. García, J. Cardesin, and M. A. Dalla Costa, "Evaluation of High-Frequency Sinusoidal Waveform Superposed with 3rd Harmonic for Stable Operation of Metal Halide Lamps." IEEE Trans. On Industry Applications, vol. 41, issue 3, pp. 721-727, May-June 2005.

[8] T.B. Marchesan, M. Cervi, A. Campos, R.N. Prado, “A family of electronic ballasts integrating power factor correction and power control stages to supply HPS lamps," IEEE Industry Application Annual Meeting (IAS) conference records, 2006.

[9] M.A. Dalla-Costa, J. M. Alonso, L. García, J. Cardesin, M. Rico, "A novel low cost electronic ballast to suply metal halide lamps," IEEE industry applications Society Meeting (IAS) Conference Records, 2005.

[10] J. F. Dums, C. B. Nascimento and A, J. Perin, "SingleStage Charge-Pump Voltage-Source Electronic Ballast for a 70 W HPS Lamp," Revista Brasileira de Eletrônica de Potência (SOBRAEP), vol. 12, March 2007, pp. 43-51.

[11] G. C. Sincero, A. S. Franciosi and A. Perin, "Reator Eletrônico para Lâmpadas de Vapor de Sódio de Alta Pressão de 250 W com Alto Fator de Potência Utilizando um Conversor CA-CA," Revista Brasileira de Eletrônica de Potência (SOBRAEP), vol. 11, November 2006, pp. 207-214.

[12] T. B. Marchesan, "Integração de Conversores Estáticos Aplicados a Sistemas de Iluminação Pública", Ph.D. tesis in Electrical Engineering (in Portuguese), Federal University of Santa Maria, Brazil, January 2008.

\section{BIOGRAPHIES}

Tiago Bandeira Marchesan was born in Santa Maria, Brazil, in 1980. He received the B.S. in 2003 (with first class honours) and the Ph.D. in 2008, both in electrical engineering from Federal University of Santa Maria, Brazil.

He has been with the electronic Ballast Research Group (GEDRE), as a researcher, since 2000. He is associated professor at the Technology Department of the Regional University of the Northwest of Rio Grande do Sul State.

His research interests include electronic ballasts, high intensity discharge lamps, lighting emitting diodes (LEDs), dimming systems, modeling and simulation of power converters.

Marco A. Dalla Costa was born in Santa Maria, Brazil, in 1978. He received the B.S. and M.Sc. degrees in Electrical Engineering from the Federal University of Santa Maria, Brazil, in 2002 and 2004, and the Ph.D. degree from University of Oviedo, Spain, in 2008.

$\mathrm{He}$ is currently a researcher working on the development of electronic systems for lighting and HID lamp modeling. His research interests include dc/dc converters, PFC stages, dimming systems, high-frequency electronic ballasts, discharge lamp modeling, and electronic starters for HID lamps.

J. Marcos Alonso received the M.Sc. degree and Ph.D. both in electrical engineering from the University of Oviedo, Spain, in 1990 and 1994 respectively. From 1990 to 1999 he was assistant professor at the Electrical and Electronic Department of the University of Oviedo, where since 1999 he is an Associate Professor.

Dr. Alonso is the primary author for more than 40 journal and international conference papers in power and industrial electronics, and has co-authored more than 100. His research interests include high-frequency electronic ballasts, discharge lamp modeling, power converters for ozone generation, power converters for electrostatic applications, power factor correction topologies and high frequency switching converters. He was the advisor of four Ph.D. Thesis students in the field of power electronics. He is the holder of four Spanish patents with two under review.

Dr. Alonso was awarded with the Early Career Award of the IEEE Industrial Electronics Society in 2006. He received the second prize paper award of the 2005 IEEE Industry Applications Society Meeting, Production and Application of Light Committee. He was also awarded with the IEEE Industrial Electronics Society Meritorious Paper Award for 1996.

$\mathrm{He}$ is an active member of the Institute of Electrical and Electronics Engineers (IEEE), where he usually collaborates as transactions paper reviewer, conference session chairman, among other positions. Since October 2002 he serves as an Associate Editor of the IEEE Transactions on Power Electronics in the field of Lighting Applications. He is also a member of the International Ozone Association (IOA). 
Ricardo Nederson do Prado was born in Itapiranga, Brazil, in 1961. He received the B.Sc. degree from the Federal University of Santa Maria, Santa Maria, Brazil, in 1984, and the M.Sc. and Ph.D. degrees from the Federal University of Santa Catarina, Florianópolis, Brazil, in 1987 and 1993, respectively, all in electrical engineering. From 1987 to 1992, he was a Professor in the Electronics Department, Federal University of Minas Gerais, Belo Horizonte, Brazil. Since 1993, he has been with the Federal University of Santa Maria, Brazil, where he is currently an associate Professor in the Electrical Energy Processing Department. From 2005 to 2006, he was with the Fraunhofer
Institute, Germany, as a Post doctoral Research Scholar. He is responsible for the Electronic Ballast Research Group (GEDRE). He has co-authored more than 140 technical papers on electronic ballast. His research directions include high-frequency high-density power converters, fluorescent and high pressure lamps, dimming systems, luminous efficiency, electronic ballasts, LED as a source light and power-factor correction.

Dr. Prado is a Founding Member of the Brazilian Power Electronics Society; He is the Member of the Brazilian Automatic Control Society, and several IEEE societies. 